plasma remaining after ${ }^{\circ}$ the removal of In spite of the general view that phlebocryoprecipitate was used as the starting material, (2) the method was relatively simple for a laboratory without a fractionation plant, (3) production could be carried out on a batch basis by one trained person, and (4) the yield of clotting factors was high.

The method has proved satisfactory. The yield of clotting factors over 25 batches was as follows: factor II, $47 \%$; factor VII, $93 \%$; factor IX, $60 \%$; factor $X, 40 \%$. The concentrates have been stored in the frozen state at $-35^{\circ} \mathrm{C}$. While this is adequate for short periods freeze-drying would be preferable. The concentrate was entirely satisfactory for the correction of clotting defects in patients with a congenital defect of factor IX and those with acquired defects of the prothrombin complex. Results to date show that a dose of concentrate, prepared from nine to ten donor-units, produces rises in factors II, VII, IX, and X of between 20 and $40 \%$. No side effects have been observed.

Though we started to make this concentrate for patients with a congenital deficiency of factor IX (Christmas disease) adequate supplies of freeze-dried concentrate for the treatment of this condition are now available from the Plasma Fractionation Laboratory, Oxford. As mentioned in your leader, the main need for this material now lies in the management of patients with acquired deficiencies of the prothrombin complex. In an attempt to assess this demand haematologists at the six teaching hospitals in our area were recently asked to estimate the number of patients who might require the material. The estimates varied between three and 36 patients a year, with an overall suggested total of 85 . While some of these patients would need only one dose (for example, to cover liver biopsy) others might need several doses for therapy.-We are, etc.,

T. W. BARROWCLIFFE Penelope Stableforth Royal Free Hospital,

KATHARINE DORMANDY

T. E. CleghorN

North London Blood Transfusion Centre,
Edgware, Middlesex

1 Bruning, P. F., and Loeliger, E. A., British fournal of Haematology, 1971, 21, 377.

\section{Diagnosis of Established Deep Vein} Thrombosis

SIR,-We were interested to read the letters of Professor J. G. Murray and Mr. P. A. Griffiths and Dr. S. Talbot (4 December 1971, p. 624), which essentially criticized the value of the 125I-fibrinogen uptake test for the diagnosis of established venous thrombosis. One of the more difficult problems of clinical medicine is the patient who presents with symptoms suggestive of deep vein thrombosis with or without symptoms suggesting a pulmonary embolus. This presentation is common and causes anxiety to both patient and doctor, especially if the patient is young. In this situation a negative ${ }^{125}$ I-fibrinogen uptake test is, in our opinion, helpful.

While agreeing with Professor Murray that phlebography will give more information about the thrombus, the 125 I-fibrinogen uptake test is simpler and after an intravenous injection can be done by a technician. graphy is the most reliable technique it is small calf vein, and we believe that the ${ }^{125}$ I-fibrinogen uptake test is the more accurate test in this area.

Both letters point out, as we did, that there are known causes of false positives and, where possible, we excluded these patients from the test. This does not mean that we did not have proper controls. One studies a test in defined clinical circumstances. Our's was a study of the use of the 125I-fibrinogen uptake test in legs where a diagnosis of deep vein thrombosis was being considered and other clinically detectable causes of similar symptoms excluded.

Mr. Griffiths and Dr. Talbot state that we were measuring only pooling of blood in the legs. There is no evidence for such a statement and much to dispute it. In the 46 legs positive by one or both methods of investigation where serial measurements were made, five of 11 changed from false negative to positive, and one of three from false positive to negative. Thus repeating the examination produced only a slight improvement in the accuracy of the test. In numerous animal studies we have data showing a high concentration of isotope within six hours of administration in thrombi known to be 14 days old. Furthermore, in our clinical study there was no evidence, phlebographically or manometrically, that any of the patients without swelling had venous obstruction. As the legs were examined in an elevated position $\mathrm{Mr}$. Griffiths's and Dr. Talbot's theoretical notion that the high count rate was due to pooling is unacceptable.

This test is not meant to replace phlebography. We use phlebography to confirm the diagnosis in most cases and as the initial method of investigation when there are local conditions in the legs such as superficial phlebitis, gross oedema, and trauma; when there is evidence of thrombosis above the mid-thigh clinically and ultrasonically; and when serial scans show the thrombus to be extending. However, for a large number of patients an initial quick screening with the ${ }^{125}$ I-fibrinogen uptake test enables us to exclude a diagnosis of venous thrombosis and avoid further investigation.-We are, etc.,

N. L. BROWSE St. Thomas's Hospital D. N. CROFT London S.E.1

\section{Physiology of Adrenal Cortical Function}

SIR,-Dr. Bertha Singer's article "Adrenal Corticosteroids - Physiological Considerations" (1 January, p. 36) was clear and concise. However, it seemed to contain some inaccuracies which might lead to misunderstanding of important aspects of pituitaryadrenal function, particularly in the clinical situation.

Firstly, it was suggested that the pigmentation of Addison's disease may result from the high plasma ACTH activity. As the study of Abe and his colleagues clearly showed, ${ }^{12} \quad \beta M S H$ is secreted whenever ACTH is secreted and is subject to the same three basic control mechanisms as ACTH -the nyctohemeral rhythm, cortisol feedback, and stress responsiveness. This is true under normal conditions and also in well known that it cannot display every
Addison's disease, Cushing's disease, both efore and after adrenalectomy, and in the ectopic ACTH syndrome. Since both are secreted in excess and in approximately equal amounts in these conditions and ACTH has only $4 \%$ of the melanotropic activity of $\beta M S H$ it seems unlikely that ACTH contributes much to the pigmentation.

Earlier in the article it was stated that the immunological reactivity of ACTH resides in the C-terminal part of the molecule, which contains amino-acids 25-39, rather than in the $\mathrm{N}$-terminal $\alpha^{1-24}$ portion responsible for steroidogenesis. Since antibody formation against tetracosactrin $\left(\alpha^{1-24}\right.$ ACTH $)$ can be demonstrated in occasional patients on long treatment with tetracosactrin-depot (Synacthen-depot, Cortrosyn-depot), it is evident that the $\mathrm{N}$-terminal portion of ACTH may be antigenic as well as the Cterminal portion. Indeed if it were not so it would be impossible to produce antisera for N-terminal ACTH radioimmunoassay. ${ }^{34}$ -I am, etc.

G. M. BESSER

The Medical Professorial Unit, St. Bartholomew's Hospital,

1 Abe, K., Nicholson, W. E., Liddle, G. W. Clinical Investigation, Orth, $D_{46} N_{\text {,i }}$ fournal of 2 Abe, K., Nicholson, W. E., Liddle. G. W., Orth, D. N., and Island, D. P., fournal of Clinical Investigation, 1969, 48, 1580 .
Besser, G. M., Cullen, D. R., Irvine, W. J. Ratcliffe, J. G., and Landon, J., British Medical Fournal, 1971, 1,374

Besser, G. M., Orth, D. N., Nicholson, W. E., Bournal of Clinical Endocrinology, 1971, 32, 595.

\section{Crohn's Disease of the Large Bowe}

SIR,-Your otherwise excellent leading article on Crohn's disease of the large intestine (15 January, p. 125) contains one important error. It states that toxic dilation does not occur. Schachter, Goldstein, and Kirsner reported ${ }^{1}$ a case, and a further five cases were reported by Javett and Brooke ${ }^{2}$ We have seen three patients with toxic dilation of the colon treated by emergency colectomy in whom the histology was typical of Crohn's disease.-We are, etc.,

J. F. FIELDING S. C. Truelove

Nuffield Department of Clinical Medicine,

Radcliffe Infirmary,

1 Schachter, H., Goldstein, M. J., and Kirsner, J. B., Gastroenterology, 1967, \$3, 136.4
Javett, S. L., and Brooke, B. N., Lancet, 1970,
2, 126.

SIR,-A misconception in your leading article (15 January, p. 125) could have serious consequences if not corrected. The categorical statement was made that toxic dilation does not occur in Crohn's disease of the large bowel. If this becomes obiter dicta any case presenting with acute dilation will be regarded as one of ulcerative colitis without question. The prognosis and management of ulcerative colitis differ considerably from those of Crohn's disease. It is therefore important to know that acute dilation can complicate any form of so-called "non-specific" inflammatory disease of the large intestine-ulcerative colitis, Crohn's disease, and ischaemic colitis. Very recently we have had a patient with toxic dilation proved histologically to be Crohn's disease- 